\title{
A PRÁTICA DE ENFERMAGEM EM HOSPITAIS DE MOSSORÓ DA TEORIA À REALIDADE
}

\author{
Taniamá Vieira da Silva Barreto * \\ José Francisco Vieira de Paulo ** \\ Ivanice de Oliveira *** \\ Valcineide Alves da Cunha Araújo ****
}

\begin{abstract}
RESUMO - Pesquisa de campo, onde buscamos caracterizar, dialeticamente, a prática do enfermeiro no interior das instituições hospitalares de Mossoró, cuja interpretação da realidade está calcada nos fatos históricos, no espaço institucional como reprodutor da ideologia dominante e a inserção do enfermeiro neste espaço. Do concreto apreendido, transparecem pontos contraditórios: (1) força de trabalho na enfermagem $X$ leitos hospitalares $(0,1 \%)$; prática do enfermeiro com ênfase no gerenciamento dos serviços $(53,8 \%) \times$ importância do cuidado direto $(34,6 \%)$; posição acrítica e de aparente neutralidade dos enfermeiros $(61,5 \%)$, cujos determinantes podem ser explicados à luz da compreensão de múltiplos fatores (divisão do trabalho na enfermagem, formação do enfermeiro, condições sócio-culturais e poder hegemônico do capital). Do exposto conlui-se pela construção do espaço do enfermeiro enquanto força representativa dos trabalhadores da enfermagem, via interpretação crítica da realidade.
\end{abstract}

\begin{abstract}
Field research, where we search to characterize, dialetically, the practice of nursing within the walls of hospital institutions of Mossoró, whose interpretation of reality is based on historical facts, as to the institutional space as reproducer of the dominant ideology and the insertion of the murse in this context. We basically discovered obvicus contradictions: (1) the work power in nursing $X$ the capacity of the hospital $(0,1 \%)$; the practice of nursing which emphasizes management services $X$ the importance of direct care $(34,6 \%)$; the noncaring atsitude and apparent indifference of nurses $(61,5 \%)$, whose determinations can be explained in the light of the comprehension of the various factors such as division of the work power and nursing care, training of the nurse, social and cultural conditions and relationship to the controlling capital. As a result, the conclusion is a construction of the nursing space as representative. of the nursing working power by the critical interpretation of reality.
\end{abstract}

\section{SOBRE A PRÁTICA DA ENFERMAGEM COMO OBJETO DA PESQUISA}

Nas décadas de 60 a 70 a América Latina passou por mudanças econômicas, políticas e sociais marcantes. Os avanços do capital e da tecnologia trouxeram, em seu bojo, o tensionamento das estruturas sociais do mundo capitalista que puseram em questão a racionalidade do Estado e a funcionalidade das políticas por este adotada.
Esse movimento da sociedade atingiu de forma particular àquelas profissōes ligadas a área humano-social e, de forma específica, na prática da enfermagem, cujo elenco de atividades ocorrem, marcadamente, no interior das instituições hospitalares.

Sob esta ótica e, reconhecendo que a prática da enfermagem é historicamente determina-

\footnotetext{
* Mestra em Enfermagem e Professora Titular do Departamento de Enfermagem da Escola Superior de Enfermagem de Mossoró/URRN

** Prof essor Adjunto IV do Departamento de Ciências Básicas da Escola Superior de Enfermagem de Mossoró/URRN e Médico Cirurgião Plástico

*** Enfermeira do Hospital Regional Tancredo Neves - Mossorठ́/II DIRES

**** Enfermeira do Centro de Saúde Santa Delmira/II DIRES
}

60 R. Bras. Enferm., Brasflia, 45 (1): 60-73, jan./mar. 1992 
da, este trabalho pretende discutir e aprofundar o estudo de questões sobre a prática de enfermagem em instituiçōes hospitalares de Mossoró, contextualizando-as em duas vertentes: a teórica e a concreticidade da realidade.

Num primeiro momento, a questão da força de trabalho em enfermagem $X$ ações desenvolvidas pelo enfermeiro aparece como elemento orientador do objeto em estudo, em busca de conhecimentos explicativos, da realidade apreendida. Posteriormente, a análise se direciona ao repensar de propostas alternativas da atuação do enfermeiro nas instituições hospitalares de Mossoró. Sua construção, no entanto, não terá um caminho linear, mas vários movimentos que permitam uma análise do objeto em estudo na sua inserção histórico-social.

Obviamente, não significa um estudo da totalidade apreendida, o que seria impossível, tendo em vista a inesgotabilidade do conhecimento.

$\mathrm{Na}$ concepção de LÖWY ${ }^{3}$ a categoria metodológica da totalidade significa a percepção da realidade social como um todo orgânico, estruturado, no qual não se pode entender um elemento, um aspecto, uma dimensão, sem perder a sua relação com o conjunto.

É nessa ótica que se resgata a compreensão da relação capital-trabalho, da assistência como política governamental, do papel da instituição na determinação do tipo de serviços de enfermagem que são oferecidos à população e a forma histórica como ocorre a prática da enfermagem, na busca de elementos explicativos da realidade apreendida.

O objeto, a Enfermagem, é colocado como uma das categorias profissionais inseridas no espaço institucional que vive momentos de crises decorrentes das contradições entre o compromisso com a população assistida e a lógica do capitalismo.

Diante deste dilema é necessário o aprofundamento teórico-metodológico do tema, com vistas a criação de estratégias, estabelecendo alianças que viabilizem, na prática, os princípios embasadores da enfermagem e que tenha como proposta a ótica do trabalho e não a ótica do capital.

Percebe-se um posicionamento utópico vinculado à perspectiva profissional de superar o praticismo, o formalismo, o burocraticismo que representam as formas ideológicas da classe dominante em legitimar a lógica institucional. Essa forma mecânica como a instituição reproduz sua prática é puro "mecanicismo assistencial que configura a exclusão enquanto mantém o trabaIhador na condição de assistićo, beneficiário ou favorecido pelo Estado e não usuário, consumidor e gestor de um serviço que tem direito" (SPOSATTI ${ }^{1}$ ). $\mathrm{Na}$ proporção que exclui também inclui, enquanto instituição que atende as necessidades de saúde da população subalternizada e desumanizada pelo capitalismo.

SPOSATTI ${ }^{1}$, fundamenta a questão dizendo que "a ação asşistencial do Estado está imbricada na relação capital/trabalho que se faz nas sequelas da exploração da força de trabalho, que, por sua vez se expressa nas precárias condiçōes de vida da classe subalternizada". Este imbricamento aparece com a mesma intensidade nas instituições da rede particular de saúde, onde transparece como objetivo maior a lucratividade e a relação de pressão da classe dominante sobre a classe trabalhadora.

A enfermagem como força de trabalho intermediadora do lucro empresarial hospitalar, está em constante crise com os seus valores ético-profissionais que preceituam o atendimento às necessidades de saúde da populaçāo como função carreadora da prática hospitalar.

É nessa ótica que se fundamenta este estudo por entendermos que um sistema social onde a maioria da população dispõe apenas de sua força de trabalho para garantir sua subsistência, o corpo $\varepsilon$ visto fundamentalmente como instrumento de trabalho que garante o processo produtivo gerador de acúmulo crescente de riquezas $\left(\right.$ SILVA $\left.^{10}\right)$.

O que se coloca é a focalização dos aspectos teórico-metodológicos da Prática da Enfermagem na rede hospitalar de Mossoró, afunilando a questão para: a) a análise da força de trabalho em Enfermagem na rede hospitalar; b) a caracterização das atividades desenvolvidas pelo enfermeiro; c) a reconstrução da totalidade da prática de enfermagem em hospitais de Mossoró, a partir da realidade apreendida.

\section{OS CAMINHOS METODOLÓgICOS PERCORRIDOS}

A observação empírica da realidade da prática de Enfermagem em instituições hospitalares de Mossoró, é uma pesquisa de caráter analítico-exploratório cujos pressupostos teóricos estão calcados na visão de sociedade, enquanto teor dialético, na proporção em que os fatos possibilitaram posicionarmo-nos como críticos da realidade apreendida. Realidade esta, que aparece como ponto de estrangulamento à normalidade funcional dos serviços ao mesmo tempo em que $\varepsilon$ a conseqüência de um conjunto de fatores sócio-históricos, sócio-econômicos e sócio-políticos.

O planejamento da investigação teve como ponto inicial o estudo da literatura existente para definirmos alguns pontos concretos relevantes à temática abordada e às questões dos serviços de enfermagem que justificassem a pesquisa.

Definida a temática buscamos o consentimento dos dirigentes hospitalares, através de 
ofício circular, focalizando o objeto de estudo e sua importância para a profissão.

Para uma melhor operacionalização da coleta dos dados e considerando o reduzido número de instituições hospitalares de Mossoró, optamos por desenvolver a pesquisa nos sete hospitais do universo pesquisado. No entanto, o tamanho populacional (60 enfermeiros) nos levou a optar por uma seleção amostral e o real coletado de 26 sujeitos, cujo método seletivo foi o da randomicidade simples e cuja representação corresponde a 43,3\% da população pesquisada; sendo assim suficiente para a produção exploratória e analítica sobre a prática de enfermagem em Mossoró.

A coleta de dados, focalizou o conhecimento das características qualitativa e quantitativa da população através de visitas aos hospitais, onde, munidos de um roteiro (Anexo 1), levantamos dados sobre as instituições, como sendo: características, capacidade, força de trabalho e serviços oferecidos.

Conhecidas as questões institucionais, partimos para a captação da percepção dos enfermeiros de instituições hospitalares de Mossoró sobre o objeto em estudo, cujo procedimento foi a discussão orientada, documentada através de registros no próprio formulário. Esse momento da pesquisa teve como instrumento convocatório e mobilizador da população um ofício circular enviado a todos os enfermeiros de serviços selecionados para compor a amostra $(43,3 \%)$ da população - 26 enfiermeiros) além de contatos pessoais com os depoentes, no sentido de garantir a efetiva participação do grupo amostral.

Munidos dos dados coletados, procedemos a leitura analítica dos mesmos, buscando traçar planos comparativos entre a realidade concreta do objeto e os pontos concretos apreendidos com a leitura do conhecimento produzido na área em estudo.

\section{EIXOS ANALÍTICOS DO OBJETO}

Embora a pesquisa tenha sido realizada em moldes funcionalistas, entendemos que a obtenção dos resultados por meios estatísticos formais, não preenche, por si só, as necessidades peculiares de uma pesquisa na área de saúde.
Para interpretação e discussão dos resultados, tentamos captar, na leitura da mensagem, não só os elementos aparentes manifestos que alguns autores chamam de denotação, mas também aqueles elementos latentes, chamados conotação (o que se encontra implícito ou não manifesto).

Assim, dentro desta perspectiva dialética de leitura da realidade consideramos que:

- o real concreto não se apresenta de forma explícita nas respostas da população pesquisada;

- a conjuntura do sistema hospitalar, que não se diferencia da conjuntura social, influencia, sensivelmente, nas respostas e práticas dos depoentes, levando a desvios e até mesmo à omissão da população pesquisada;

- na sociedade capitalista os fenômenos da Enfermagem são produtos dessa sociedade dividida em classes e de interesses antagônicos;

- a instituição hospitalar, constitui-se num espaço contraditório que permite, ao Enfermeiro, realização de um trabalho que responda aos interesses, tanto da instituição como dos pacientes e da Enfermagem.

A análise dos dados, por questões investigadas, constitui-se, certamente, a forma mais viável de apresentação dos resultados da pesquisa, ficando categorizada em Eixos Analíticos do Tema, tais como: caracterização do universo pesquisado e sua força de trabalho, a Enfermagem na contradição entre capital e trabalho e o real concreto da prática de Enfermagem.

\subsection{Caracterizaçāo do universo pesqui- sado e sua força de trabalho:}

Os dados deste estudo revelam a existência de 7 (sete) hospitais e 993 (novecentos e noventa e três) leitos, onde trabalham 60 (sessenta) enfermeiros, 46 (quarenta e seis) técnicos de Enfermagem, 113 (cento e treze) auxiliares de Enfermagem e 379 (trezentos e setenta e nove) atendentes de Enfermagem, distribuídos de forma bastante desigual entre os serviços públicos e privados e apresentando grandes flutuações em termos quantitativos, quando se considera o tamanho dos hospitais - vide Quadro 01. 
Quadro 01 - Força de trabalho em Enfermagem, por hospitais e leitos públicos e privados em Mossoró - Agosto/1991.

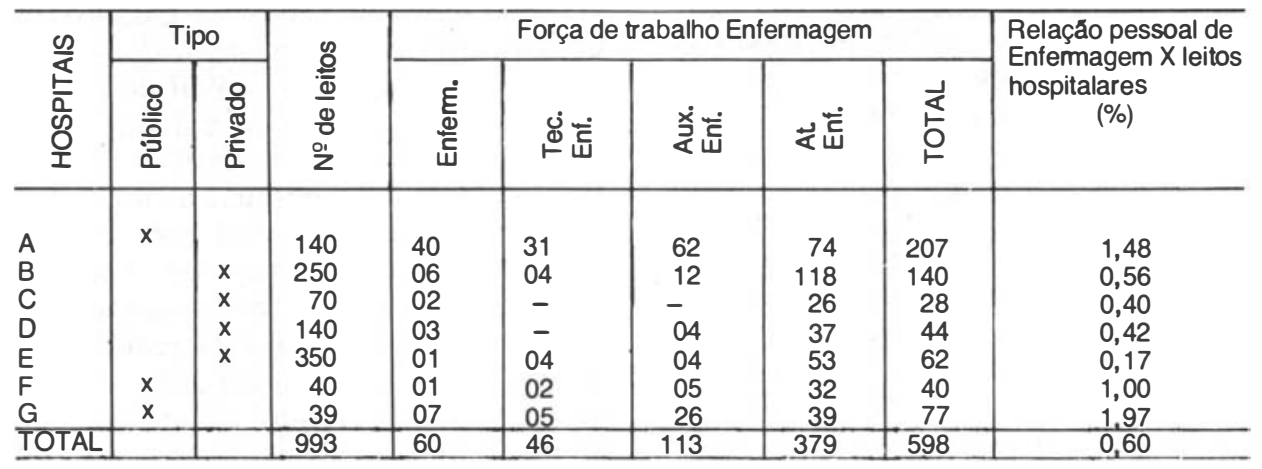

É por essa linha que se procura conduzir a apresentação das categorias analíticas do tema, considerando, sempre que necessário, a divisão dos hospitais em públicos e privados.

Pode-se perceber que a assistência hospitalar prestada por hospitais públicos alcança a menor parcela da população, pois apenas $42,9 \%$ dos hospitais e $22,1 \%$ dos leitos existentes em Mossoró não são privados. Assim, o setor opera dentro de um quadro empresarial compatível com o desempenho do processo de desenvolvimento capitalista, onde a crescente acumulação de capital nas atividades faz com que o Estado deixe de oferecer os serviços de saúde, passando a ser também comprador dos serviços particulares; "capital e Estado se aliam e o contribuinte não chega a ser o beneficiado" (COFEN/ABEN). Este fato talvez seja significativo para que se visualize, no concreto observado, a discrepância quantitativa entre as quatro categorias (enfermeiros, técnicos de Enfermagem, auxiliares de Enfermagem e atendentes de Enfermagem) constitutivas da força de trabalho na Enfermagem da rede hospitalar de Mossoro, onde constatamos que, dos 274 (duzentos e setenta e quatro) trabalhadores do setor privado, a categoria Enfermeiro representa apenas 4,4\%Quadro 02. Disto há de se considerar a população pesquisada como uma pequena fração dos protagonistas dos serviços de Enfermagem inserida no contexto hospitalar, decorrente da própria divisão técnica do trabalho, via processo de produção capitalista. Esta discrepância se agrava quando inferimos na análise, os dados do Quadro 01, onde a relação pessoal de Enfermagem e número de leitos hospitalares demonstram uma variação no setor privado de $0,17 \%$ a $0,56 \%$, enquanto que no setor público, é de $1,00 \%$ a $1,97 \%$. Estes dados nos alerta para a disparidade na absorção do pessoal de Enfermagem em Mossoro, entre os hospitais públicos e privados, ficando evidente a existência de atendimentos diferenciados nos dois serviços, onde a mão-de-obra desqualificada e barata é utilizada como forma de favorecer a acumulação de capital. Mesmo assim, a classe menos favorecida ressente-se por não usufruir dos serviços médicos particulares.

Quadro 02 - Demonstrativo da força de trabalho em enfermagem por hospitais públicos e privados em Mossoró - Agosto/1991.

\begin{tabular}{|c|c|c|c|c|c|c|c|c|c|}
\hline \multirow{3}{*}{$\frac{\text { CATEGORIAS }}{\text { Enfermeiros }}$} & \multicolumn{6}{|c|}{ HOSPITAIS } & \multirow{2}{*}{\multicolumn{3}{|c|}{ TOTAL }} \\
\hline & \multicolumn{3}{|c|}{ PÚBLICOS } & \multicolumn{3}{|c|}{ PRIVADOS } & & & \\
\hline & 48 & - & 14,8 & 12 & - & 4,4 & 60 & - & 10,0 \\
\hline Téc. Enfermagem & 38 & - & 11,7 & 08 & - & 2,9 & 46 & - & 7,7 \\
\hline Aux. Enfermagem & 93 & - & 28,7 & 20 & - & 7,3 & 113 & - & 18,9 \\
\hline At. Enfermagem & 145 & - & 44,8 & 234 & - & 85,4 & 379 & - & 63,4 \\
\hline TOTAL & 324 & - & 100,0 & 274 & - & 100,0 & 598 & - & 100,0 \\
\hline
\end{tabular}

Esta penetração da iniciativas privada no setor hospitalar de Mossoro, retrata claramente a realidade apreendida pelos estudos do $\mathrm{CO}$ FEN/ABEN onde no Nordeste, o contingente atendente chega a $70,0 \%$ da força de trabalho em Enfermagem. É necessário explicitar, contudo, que, seja no público ou privado, há a existência concreta da exploração capital $x$ trabalho, onde as instituições privilegiam a mão- de-obra do atendente em detrimento da qualidade dos serviços que são of erecidos a população.

Carece de explicitação também, o fato de que no interior dessas instituições as propostas do governo são fundamentadas em uma visão funcionalista, priorizando uma política curativa; haja vista que eliminada a patologia, o paciente retorna ao mercado de trabalho como força produtiva. A patologia aqui é vista como causa 
biológica, dissociada dos determinantes sociais.

LUZ $^{4}$ vem complementar o exposto quando discute a idéia de que a hegemonia nas instituições médicas tem suas raízes no modo de produção capitalista, constituindo-se um veículo reprodutor, transmissor e elaborador do saber político-ideológico dominante. É nesse espaço que a instituição médica se apropria dos profissinais da área de saúde para fortalecer o seu discurso de "prioridade maior na assistência e bem-estar ao paciente" para legitimar a ideologia dominante desejável e aceitável pelos usuários dos serviços hospitalares. Na intermediação desse espaço político, o Enfermeiro coloca-se em posição dicotômica entre o seu real papel profissional gerenciador de uma assistência $X$ cuidado direto ao paciente e o papel do hospital (o de acumulação de capital).
Merece_ser inferido nesta reflexão do real concreto observado, o significativo contingente do sexo feminino (96,3\% - Quadro 03) na força de trabalho na Enfermagem de Mossoro, reforçando a ideologia do capital de divisão de classes e o barateamento do trabalho produzido pelas categorias que compõem os trabalhadores de Enfermagem. Isto porque, historicamente, o trabalho da mulher tem sido visto como desvalorizado quando comparado com o trabalho do homem. Este agravante representa uma das vertentes históricas da leitura da realidade da prática de Enfermagem, cujo estigma social (profissão basicamente feminina) emperra o processo de desenvolvimento da profissão, via conquista de seu "status" como prática profissional.

Quadro 03 - Demonstrativo da força de trabalho em enfermagem por categoria e sexo na rede hospitalar de Mossoró - Agosto/1991. 598 sujeitos.

\begin{tabular}{|c|c|c|}
\hline SEXO & MASCULINO & FEMININO \\
\hline CATEGORIAS & Quantidade (\%) & Quantidade (\%) \\
\hline Enfermeiros & $03-0,5$ & $57-9,5$ \\
\hline Técnicos de Enfermagem & --- & $46-7,7$ \\
\hline Auxiliar de Enfermagem & --- & $113-18,9$ \\
\hline Atend. de Enfermagem & $19-3,2$ & $360-60,2$ \\
\hline$\overline{\text { TOTAL }}$ & $22-3,7$ & $576-96,3$ \\
\hline
\end{tabular}

\subsection{A Enfermagem na Contradiçāo entre} Capital e Trabalho - concepçāo histórico-política da prática profissional

Inicialmente merece ser destacado que a divisão social do trabalho corresponde diretamente a condição dos indivíduos terem profissões distintas. Isto, $\varepsilon$ inerente às mais diversas formações econômicas, sendo que são as formas especifficas da divisão do trabalho, que pertencem a este ou aquele modo de produção *, fonte de desigualdade social, reproduzindo as relações políticas e ideológicas das diferentes classes sociais. Essa desigualdade é marcante nos serviços de enfermagem quando ações de atenção ao doente são desenvolvidas por categorias diferentes (Enfermeiros, técnicos, auxiliares e atendentes), onde a relação de poder retrata a divisão técnica do trabalho na enfermagem.

A análise do movimento histórico da prática do cuidado ao doente demonstra que no período antes de Cristo já havia o preparo de pessoas com algumas habilidades e conhecimentos para cuidar do doente: sacerdotes, feiticeiros e mulheres de modo geral prestavam tais cuidados, existindo em alguns povos, a exemplo do Egito, distinção entre os sacerdotes que cuidavam dos

ricos e outra categoria de sacerdotes que prestavam cuidados aos pobres (PAIXÃO $\left.{ }^{8}\right)$. Na prática de enfermagem no interior dos hospitais particulares esta distinção é marcante, pois os leitos pagos pelo Estado são atendidos (assistidos) por aqueles profissionais com menos qualificação técnica e de relações humanas; até a aparência influi no momento do enfermeiro designar os profissionais para atendimento àquelas pessoas de maior poder aquisitivo (pacientes de apartamento).

De atribuição dos estrangeiros e escravos na Roma antiga, a Enfermagem passa, na idade média, a ser desenvolvida pelos religiosos, sendo que, o trabalho de enfermagem, na sua origem, esteve sempre associado ao trabalho feminino, pouco valorizado socialmente de acordo com o papel designado às mulheres pela sociedade de classes.

Não é por natureza que a mulher realiza o chamado trabalho doméstico, muito menos as atividades dar decorrentes. As tipologias sexuais hoje existentes são também um produto da divisão do trabalho. Parece claro que o estigma

\footnotetext{
* $\mathrm{O}$ aprofundamento desta vertente pode ser obtido com a leitura do capítulo sobre as classes do Livro Terceiro - O processo global da produção capitalista, de Karl Marx, in: O Capital, Vol. V da Ed. Nova Cultural 1988, pág. 297.
} 
de que a enfermagem é uma profissão basicamente feminina continua até nossos dias; pois os dados do Quadro 03 evidenciam que apenas $3,7 \%$ da força de trabalho na enfermagem do universo em estudo é do sexo masculino. Este percentual diminui para $0,5 \%$ quando analisamos a categoria do Enfermeiro isolada das demais categorias da Enfermagem. Introduzida nos hospitais através das religiosas, a enfermagem desenvolve seu trabalho calcado numa filosofia religiosa de amor ao próximo (sacerdócio) enquanto que a medicina é vista como profissão (prática urbano-corporativa).

A prática da enfermagem em Mossoró tem também origem histórica nas ações religiosas, onde as irmãs franciscanas, muitas vezes sem nenhum preparo, assumiam, totalmente os serviços de enfermagem do então Hospital de Caridade de Mossoro, hoje Hospital Duarte Filho. Esta situação veio se reverter com o funcionamento da Escola Superior de Enfermagem de Mossoró - ESEM/FURRN em 1971, quando o mercado de trabalho local passou a absorver enfermeiros graduados por aquela Unidade de Ensino Superior (UES).

A reforma protestante, no séc. XVI, traz em seu bojo a ascenção do capital e a decadência da enfermagem, com o fechamento de hospitais e expulsão dos religiosos que ar atuavam $\left(\mathrm{PAIXÃO}^{8}\right)$. A partir de então, passa-se a recrutar pessoal leigo e remunerado para executar os serviços de enfermagem, em sua maioria, mulheres marginalizadas que, em troca de baixos salários vendiam sua força de trabalho para a prestação de serviços variados; entre eles, o cuidado aos doentes, ficando claro que o corpo do trabalhador é visto apenas como instrumento de produção de trabalho.

A utilização das mulheres para desempenharem esse papel reflete a ideologia de uma, sociedade onde o trabalho manual era menosprezado e, como tal, relegado à categoria considerada inferior. Nos hospitais, as atividades dos serviços eram muito mais uma caracterização do trabalho doméstico designado para o sexo feminino como conseqüência da divisão do trabalho entre os diferentes sexos, que reflete as bases da relação de dominação do sexo masculino sobre o sexo feminino e o papel subordinado da mulher como "doméstica e mãe".

Com a queda do feudalismo e o surgimento do mercantilismo com forma de produção dominante, advinda das transformações econômicas e políticas, ressurge a organização hospitalar originada das congregações religiosas com designação de um elemento feminino para dirigir os serviços e outras mulheres encarregadas das enfermarias. Constitui-se ar o inf́cio da divisão do trabalho, onde os elementos designados para prestarem os cuidados reproduzem dentro da instituição hospitalar, a hierarquia religiosa que, por sua vez, é inspirada na organização militar.

$\mathrm{Na}$ concepção de $\mathrm{MELO}^{6}$ há na organização dos serviços de enfermagem, mesmo dominado pelas instituições religiosas, duas categorias de serviçais: "o coordenador e o executor" do cuidado. Essa divisão, inerente das diversas formações econômicas da sociedade, reflete na prática da enfermagem e a divisão entre o trabalho manual e o intelectual que encontra compreensão nas relações políticas e ideológicas. A mesma autora, citando Poulontzas e Gonçalves, coloca que essa divisão "não se limita a divisão técnica do trabalho, mas constitui de fato, em todo modo de produção dividido em classes, a expressão concentrada de correspondência das relações políticas e ideológicas, na sua articulação com as relaçōes de produção".

$\mathrm{MELO}^{6}$ continua sua análise, colocando que os problemas de saúde ampliados pela Revolução Industrial, convergiam para três questões: as grandes epidemias que atingiram burgueses e proletários; as péssimas condições de vida e de saúde que reduziam a produtividade do trabalhador e os movimentos da classe operária, contra suas condições de vida e trabalho. Era necessário portanto, medidas para que se pudesse conter os conclamos da população, tendo o Estado assumido este papel.

Em conseqüência, os serviços de saúde institucionalizados impõem normas individuais de comportamento, visando a produção da saúde da população. Ao mesmo tempo, o desenvolvimento da ciência médica, a reorganização dos hospitais com novos objetivos e sob a direção do médico, e incorporação de enfermeiros ao pessoal hospitalar, possibilitam as bases para o novo caráter da intervençáo do Estado na saúde.

É no hospital que se concentram os instrumentos sofisticados de trabalho, possibilitando a produção de serviço em grande escala, e reforçando o seu papel enquanto núcleo do aparelho ideológico do Estado, reproduzindo as práticas sociais referentes a produção de serviço de saúde $\left(\mathrm{MELO}^{6}\right)$.

O que se coloca no século XIX é que sem as condições antissépticas, nutrição adequada, monitoria pré e pós-operatórias e cuidados com a reabilitação, nenhum diagnóstico ou capacidade cirúrgica conseguiram salvar vidas. E é justamente sobre a égide dos princípios assépticos, de higiene e nutrição que surge a enfermagem moderna, cujos cuidados são desenvolvidos de forma contínua durante as $\mathbf{2 4}$ horas, enquanto que os médicos limitavam-se a curtas visitas ao paciente $\left(\mathrm{MELO}^{6}\right)$.

Da realidade apreendida neste estudo constata-se que, transcorridos mais de cem anos, a prática de assistência hospitalar ao paciente recai sobre o pessoal de enfermagem enquanto 
que ao médico compete, apenas, rápidas visitas diárias, sendo que, na maioria das vezes, este profissional passa vários dias sem visitar o paciente.

Há de se ressaltar que a maior parte dos cuidados de enfermagem é delegado a pessoal não qualificado tecnicamente, pois $63,4 \%$ da força de trabalho em enfermagem do universo pesquisado é constituída de atendentes contra $10,0 \%$ de enfermeiros (Quadro 02). Esta realidade se amplia quando analisamos a força de trabalho dos hospitais privados $(85,4 \%)$ contra $44,8 \%$ dos hospitais públicos. Isto significa que a mão-de-obra barata é utilizada como forma de privilegiar a produtividade em detrimento da qualidade. $\mathrm{O}$ que se deduz é que o enfermeiro concentra suas funções em atividades burocrático-administrativas, reforçando a divisão técnica do trabalho e a própria divisão de classes do sistema capitalista vigente.

É importante resgatar aqui, a origem histórica da enfermagem moderna, quando Florence Nightingale concentra suas atividades, principalmente, na área administrativa e treinando mulheres para a prestação dos cuidados diretos aos pacientes. Assim, a divisão do trabalho na enfermagem aparece para atender a um modelo de política de saúde imposto, que é a forma com que o Estado interfere sobre a organização social de produção e consumo dos serviços de saúde (TEIXEIRA ${ }^{12}$ ), ao mesmo tempo em que reproduz a estrutura de classes da sociedade capitalista, através da hierarquização profissional, onde a própria divisão do trabalho intelectual manual tem sua origem histórica nos primórdios da enfermagem moderna (Sistema Niglitingaliano). Esta divisão se fortalece a partir da expansão técnica e burocrática das inatituições hospitalares e com a legitimação do pessoal auxiliar com a lei número 795/1949, que cria, oficialmente, os cursos de Auxiliares de Enfermagem.

NAKAMAE ${ }^{7}$ faz uma análise da formação dos trabalhadores de enfermagem, enfatizando que esta se deu, desde suas origens, vinculada a das classes dicotômicas: o proletariado, formando-se em atendentes, mais tarde, candidatos aos cursos de auxiliar; e a burguesia, formando-se enfermeiras; ambas, basicamente feminina.

O desdobramento no entanto, da expansão do pessoal de enfermagem, faz com que ao atendente caiba a maior parte das tarefas relacionadas com o cuidado do paciente, mesmo sem preparo adequado. Esta realidade está bem transparente no universo deste estudo com o contingente de $63,4 \%$ da categoria atendente Quadro 02, merecendo ser entendida a luz da historicidade da prática de enfermagem.
Com a ampliação da divisão social do trabalho no século XX, decorrente do avanço tecnológico e surgimento de novas políticas de saúde, sob a égide do capitalismo, surgem novas categorias de enfermagem encarregadas do cuidado direto ao paciente. Assim, o enfermeiro se apropria do trabalho de supervisão e controle, reafirmando o seu papel de trabalhador intelectual da enfermagem, dono de um saber, inicialmente técnico que, com a institucionalização do ensino, se amplia para os princípios científicos da administração (saber administrar, supervisionar e ensinar), garantindo uma posição privilegiada na divisão social do trabalho, adaptando-se assim, ao modo de produção dominante. Esta divisão reflete a própria organização do processo de trabalho; profissão que depende das relações de produção e que domina, inclusive, a própria divisão técnica do trabalho. Ela não é apenas uma divisão de tarefas manuais ou mais intelectuais entre pessoas de classes sociais diferentes; mas, a manifestação da existência de diferentes formas de propriedades e da desigualdade social; e, por isso mesmo, tende a se ampliar sob o modo de produção capitalista.

É nesta ótica da organização do trabalho que a enfermagem se apropria dos aspectos das teorias de TAILOR e FA YOL * para efetivar "a delegação de funçōes e atividades $e$, conseqüentemente, da responsabilidade, que obedece à lógica da divisão técnica do trabalho e que se reflete de modo especial na divisão do trabalho entre enfermeiros, técnicos, auxiliares e atendentes de enfermagem" $\left(\mathrm{MELO}^{6}\right)$.

Do ponto de vista do capital, o trabalho da enfermagem é improdutivo e assalariado por se apresentar sob forma de serviço que é trocado por salário. Sua inserção nos serviços de saúde permitiu e permitirá a modificação permanente da apresentação e a qualidade do trabalho em si, mas, ainda não o transformou, a ponto de o considerarmos como trabalho produtivo. O que podemos afirmar é que o produto ou atividade do trabalho da enfermagem é consumido como valor de uso, considerando que "serviço nada mais é que o efeito útil de um valor de uso, se ja ele mercadoria ou trabalho" $\left(\mathrm{MARX}^{5}\right)$. Na prestação de serviço de enfermagem, o efeito útil do trabalho não toma a forma de um objeto ou mercadoria, mas é um trabalho oferecido diretamente ao consumidor. Sendo assim, o trabalho na enfermagem seria nada mais que o efeito útil de um valor de uso, seja ele mercadoria ou trabalho, e isto não o caracteriza como trabalho produtivo; mas como trabalho assalariado que produz capital, ou seja, como trabalho que possui o caráter de elemento criador de valor-detroca. Isto não quer dizer que o trabalho na enfermagem não seja explorado e não sofra de-

\footnotetext{
* Cientistas da administração, TAYLOR e FAYOL estudaram a adaptação do trabalho às necessidades do capital e organização
do trabalho, respectivamente; ambas as teorias são voltadas para a harmonia e o autoritarismo.
} 
terminações do modo de produção capitalista, quando se sabe que o setor serviço pode contribuir para acumular capital, mas não para produzir mais valia, no sentido clássico deste conceito.

\subsection{O real concreto da Prática de En- fermagem em Mossoró}

É importante descatar que a reflexão sobre o tema pauta em analisar a prática do cotidiano do Enfermeiro no interior das instituições hospitalares. Esse repensar não implica em of erecer um modelo, mas extrair da estrutura dessa prática subsídios para reestruturá-la, dentro de uma visão conjuntural, já que os hospitais em estudo carecem de uma força de trabalho compatível com a demanda dos serviços, tanto em quantidade como em qualidade profissional (ver Quadro 01).

NAKAMAE $^{7}$ ressalta que o processo de minimização dos custos com vistas a maximização dos lucros não se evidencia apenas no caso de direção administrativa dos serviços de Enfermagem; mas atinge a esta em todos os níveis de trabalho, fazendo prevalecer esse critério sobre os demais; como por exemplo, o da prioridade na preservação ou elevação da qualidade da assistência, tão alardeada em nível de discurso.

Contrapondo-se a este discurso apenas $23,1 \%$ dos depoentes situam a assistência ao paciente dentre as atividades desenvolvidas, por eles - Quadro 04. Tem-se, ar exposto, as raízes da manutenção da diferenciação atual das categorias profissionais atuantes no setor, tornando-se claro, pois, o equívoco das posições que correlacionam a reduzida presença do enfermeiro nas instituições de saúde à sua suposta escassez, como bem mostram os dados distribuídos nos Quadros 01 e 02 desta pesquisa. Contraditoriamente, o Enfermeiro é demandado pelo mercado por sua competência e como ocupante do lugar de controle da força do trabalho manual na rígida disciplina do hospital, mas também dispensada dele pela práxis capitalista em reduzir custos com aproveitamento de pessoal menos qualificado e mais barato. As transformações porque passou a Enfermagem, do pre-capitalismo ao capitalismo, reservou um lugar para os Enfermeiros na divisão social do trabalho, que diz respeito, sobretudo, ao desempenho de atividades administrativas e de ensino.

"No salto da Enfermagem tradicional para a moderna", também o seu objeto de trabalho se transformou, não se constituindo mais no cuidado direto, mas na supervisão da assistência de Enfermagem.
Configura-se no Quadro 04 a "organização e administração do setor, a supervisão de toda a equipe de Enfermagem e a assistência aos postos de Enfermagem, aos médicos e à equipe de Enfermagem" $(53,8 \%)$ como principais atividades desenvolvidas pelo Enfermeiro, deixando claro a sua contribuição indireta na produção e na extração da mais-valia *, uma vez que, como categoria privilegiada entre os demais trabalhadores da Enfermagem, coloca-se como reprodutor dos objetivos institucionais. Estes por sua vez, são orientados pela visão social capitalista.

Nosso ponto de vista é de que o passo seguinte não $e$ o de renunciar ao cuidado direto ao paciente, mas o de resgatá-lo ou conquistá-lo através do assumir de uma postura crítico-reflexiva da realidade do espaço de trabalho do Enfermeiro. Deste resgate ou conquista advirá a assistência de Enfermagem integralmente praticada, possibilitando a qualidade do cuidado tão enfatizada em nível de discurso ideológico e sempre relegada a plano inferior na prática, por exigência da autovalorização do capital. A perspectiva a ser conquistada não é a de apenas manter ou repor em pé a força de trabalho submetida ao capital, mas de priorizar a saúde em sua forma plena (NAKAMAE ${ }^{7}$ ).

O movimento na leitura dos dados do Quadro 04 nos possibilita apreender que o Enfermeiro, mesmo com menor significado estatístico, se comparado com as variáveis de cunho administrativo $(53,8 \%)$, desenvolve atividades de assistência direta aos pacientes mais graves $(23,1 \%)$ que necessitem de "técnicas mais complexas da enfermagem, como sendo: passar sondas, realizar curativos, fazer aspirações e controles, etc" $(7,7 \%)$ e evolução dos pacientes $(7,7 \%)$.

Inferindo neste ponto as concepções teóricas dos conhecimentos produzidos na área de enfermagem analisadas por ALMEIDA ${ }^{1}$, fica claro o contra-ponto da questão em nível de discurso. Senão vejamos: o ponto concreto que se verifica na atuação cotidiana do enfermeiro nas instituições hospitalares é o assumir de conduta organizada segundo rotinas pré-estabelecidas, em cumprimento aos regulamentos burocráticos que se confirma com as atividades de supervisão, organização e assessoria (funções administrativas); e o contraponto está no que se espera do enfermeiro, na visão das teoristas da enfermagem, ao definirem como seu objeto de trabalho, o cuidado e no processo de sua formação profissional, quando os enfermeiros aprendem a valorizar o cuidado individualizado aos pacientes, com base nos conhecimentos científicos. Mas, aprofundando este pensamento, e recolocando-o no contexto da realidade concreta apreendida, questionamos: como pode

(3) O aprofundamento desta vertente pode ser obtido com a leitura do Dicionário de Economia de Paulo SANDRONI, pág. 182. 
o enfermeiro prestar o cuidado individualizado ao paciente num sistema tão contraditório (no de enfermeiros X demanda de pacientes - Quadro 1)?

\section{Quadro 04 - Demonstrativo das atividades dos depoentes - Mossoró-RN - Agosto/1991 - 26 depoentes}

\begin{tabular}{|c|c|c|}
\hline $\begin{array}{l}\text { Questōes } \\
\text { Investigadas }\end{array}$ & Variáveis & $\begin{array}{c}\text { Total } \\
\text { Quantidade \% }\end{array}$ \\
\hline $\begin{array}{l}\text { 1. Que Atividades você exe- } \\
\text { cuta? }\end{array}$ & $\begin{array}{l}\text { a) Organização e administração do setor (escala, controle de freqüéncia, } \\
\text { censo, etc.). } \\
\text { b) Exame, evolução e avaliação do paciente. } \\
\text { c) Assistência aos pacientes de maior gravidade e familiares. } \\
\text { d) Supervisão de toda a equipe de enfemagem. } \\
\text { e) Assitência aos postos de enfermagem, aos médicos e à equipe de en- } \\
\text { femagem. } \\
\text { f) Técnicas mais complexas da enfermagem (S.N.G., curativos, aspi- } \\
\text { ração, controles, etc.). } \\
\text { g) Evolução dos pacientes. } \\
\text { h) Não responderam. }\end{array}$ & $\begin{array}{l}14-53,8 \\
02-7,7 \\
06-23,1 \\
14-53,8 \\
14-53,8 \\
02-7,7 \\
02-7,7 \\
12-46,1 \\
\end{array}$ \\
\hline $\begin{array}{l}\text { 2. Das atividades que vocé } \\
\text { executa qual a que vocé } \\
\text { considera a mais prioritá- } \\
\text { ria? }\end{array}$ & $\begin{array}{l}\text { a) Assitência direta ao paciente. } \\
\text { b) Assitência a equipe de enfermagem. } \\
\text { c) Examinar o paciente e avaliar. } \\
\text { d) Não responderam. }\end{array}$ & $\begin{array}{l}09-34,6 \\
05-19,2 \\
02-7,7 \\
13-50,0\end{array}$ \\
\hline $\begin{array}{l}\text { 3. Quais os documentos ad- } \\
\text { ministrativo que vocé } \\
\text { dispōe no seu setor? }\end{array}$ & $\begin{array}{l}\text { a) Nomas. } \\
\text { b) Rotınas. } \\
\text { c) Ficha de levantamento de faltas. } \\
\text { d) Ficha de avaliação do desempenho. } \\
\text { e) Não responderam. }\end{array}$ & $\begin{array}{l}08-30,8 \\
06-23,1 \\
10-38,5 \\
10-38,5 \\
16-61,5\end{array}$ \\
\hline
\end{tabular}

O que pode ser colocado como ponto de crítica é que o enfermeiro desempenha um papel que não lhe foi passado durante a formação e, talvez por isto é que há lacunas bem transparentes no que concerne sua competência técnica para administrar. Esta colocação está bem confirmada no Quadio 04 com a afirmação dos depoentes de que os instrumentos administrativos utilizados nos serviços são, basicamente: "normas $(30,8 \%)$, rotinas $(23,1 \%)$, fichas de levantamento de faltas $(38,5 \%)$ e ficha de avaliação do desempenho $(38,5 \%)$ ". Vale ressaltar que $61,5 \%$ dos depoentes não se posicionaram sobre esta questão quando $53,8 \%$ ressaltam as funções administrtivas como atividades desenvolvidas pelo enfermeiro no seu cotidiano profissional, sendo que estas ficam em nível do subjetivo sem uma colocação mais aprofundada e mais ampla das atividades. Isto, certamente, encontra justificativa na questão do despreparo técnico do enfermeiro para o gerenciamento. Disto apreendemos que, mesmo desenvolvendo atividades administrativas, $7,7 \%$ deste conteúdo amostral não consegue identificar os instrumentos administrativos necessários à sua prática.

Fazendo o resgate da origem da enfermagem moderna, quando Florence Nightingale privilegia os cargos administrativos como agentes de mudanças na estrutura hospitalar, constatamos que a dicotomia entre o cotidiano da prática do enfermeiro e o processo de sua formação deve ser interpretada também a luz da historicidade e da relação de poder das instituições hos- pitalares $\mathrm{X}$ categorias da enfermagem, via modo de produção capitalista. CASTELLANOS referenda esta posição da prática da enfermagem ao afirmar que o seu projeto de trabalho varia, quando analisado, a luz das categorias, ou seja: os enfermeiros têm prioritariamente, como objeto de trabalho as atividades gerenciais e de ensino e as "demais categorias (técnicos, auxiliares e atendentes) têm como objeto de trabalho o cuidado direto". Colocando-se sobre este ponto, TREVIZAN ${ }^{13}$ cita três fontes propiciatórias do trabalho do enfermeiro: (1) a própria enfermagem, com a adoção de uma divisão técnica de trabalho, já presente nos primórdios da enfermagem modema; (2) a organização hospitalar que coloca o enfermeiro (por ter presença física contínua e obrigatória, na instituição) como representante da subestrutura administrativa, social e física, embora não faça parte dela; e, (3) a expectativa médica de que o enfermeiro seja o protetor do conhecimento médico, atuando como especialista administrativo, controlando a assistência e o acesso à informação sobre os pacientes, o que facilita o fluxo do conhecimento.

Do que é colocado pelos depoentes nos faz apreender que a prática do enfermeiro carece de embasamentos teóricos consistentes. A visão unicasual dos fenômenos que emperram o processo de trabalho na enfermagem contrapõe-se ao nosso entedimento da prática de enfermagem social e historicamente determinada.

$\mathrm{O}$ viés que se apresenta nesse contexto é de que a assistência à saúde no Brasil se dá, fun- 
damentalmente, pela execução de ações de caráter curativo. Nesse sentido, a atuação do enfermeiro está concentrada nos hospitais. Mesmo assim, os hospitais, tanto em nível público como privado, na perspectiva de reproduzir a ideologia capitalista vigente, configuram na sua força de trabalho na enfermagem o predomínio de categorias em níveis médio e elementar (auxiliares e atendentes de enfermagem).

\section{Quatro 05 - Demonstrativo da realidade da prática de Enfermagem - Mossoró-RN - Agos- to/1991 - 26 depoentes}

\begin{tabular}{|c|c|c|}
\hline $\begin{array}{l}\text { Questỏes } \\
\text { Investigadas }\end{array}$ & Variáveis & $\begin{array}{c}\text { Freqüência } \\
\text { Quantidade \% }\end{array}$ \\
\hline $\begin{array}{l}\text { 1. Deteminantes das } \\
\text { más condiçōes de tra- } \\
\text { balho de Enfermagem. }\end{array}$ & $\begin{array}{l}\text { a) falta de material e medicamento } \\
\text { b) profissionais que trabalham com má vontade e sem amor a } \\
\text { profissão } \\
\text { c) falta de condiçōes financeiras do paciente faz com que ele } \\
\text { retorne rapidamente ao serviço } \\
\text { d) falta de humildade e humanismo } \\
\text { e) falta de profissionais qualificados (técnicos e auxiliares) } \\
\text { f) curto período de internação do paciente } \\
\text { g) poucos funcionários } \\
\text { h) funcionários sem qualificação para assisténcia } \\
\text { i) no de leitos insuficientes para atender a demanda } \\
\text { j) falta de parâmetros para proteção dos funcionários } \\
\text { l) não responderam }\end{array}$ & $\begin{array}{l}06-23,1 \\
06-15,4 \\
03-11,5 \\
06-23,1 \\
14-53,8 \\
02-7,7 \\
14-53,8 \\
14-53,8 \\
05-19,2 \\
06-23,1 \\
12-46,2\end{array}$ \\
\hline $\begin{array}{l}\text { 2. Mudança necessárias } \\
\text { para a melhoria da } \\
\text { prática do enfermeiro. }\end{array}$ & $\begin{array}{l}\text { a) aumentar o no de funcionários especializados } \\
\text { b) treinamento sobre relações humanas } \\
\text { c) sistematização de um trabalho de prevenção, tratamento e } \\
\text { reabilitação do paciente } \\
\text { d) utilização de materiais descartáveis } \\
\text { e) um eficiente serviço de manutenção } \\
\text { f) não responderam }\end{array}$ & $\begin{array}{l}14-53,8 \\
06-23,1 \\
05-19,2 \\
07-26,9 \\
08-30,8 \\
12-46,2\end{array}$ \\
\hline $\begin{array}{l}\text { 3. Qual o seu conheci- } \\
\text { mento sobre a Lei do } \\
\text { Exercicio Profissional? }\end{array}$ & $\begin{array}{l}\text { a) é a lei que ampara todas as nossas atividades } \\
\text { b) proibe a prática do aborto e eutanásia } \\
\text { c) para exercer a profissão temos que ser inscritos no COREN } \\
\text { d) não responderam }\end{array}$ & $\begin{array}{l}11-42,3 \\
09-34,6 \\
13-50,0 \\
12-46,2\end{array}$ \\
\hline
\end{tabular}

Com isto, o desenvolvimento da prática do enfermeiro (aliás, como os demais profissionais com função social) no interior dos hospitais encontra dificuldades marcantes, seja pela falta de pessoal qualificado para as atividades dos serviços seja pelo acúmulo de tarefas do enfermeiro, fazendo-o delegar aos atendentes, atribuições que só a ele compete *.

Nesta vertente, parece claro que os enfermeiros desconhecem (ou pelo menos, conhecem pouco) os princípios da Lei do Exercício Profissional, pois, quando argüidos a se posicionarem sobre o conteúdo da mesma, limitaram a definí-la como a "lei que ampara todas as nossas atividades" (42,3\%); e impõe-nos a condição de que, "para exercer a profissão, temos que ser inscritos no COREN" (50,0\%) - dados do Quadro 05. Esta afirmativa está reforçada no fato de $46,2 \%$ dos depoentes se omitirem sobre o assunto e, $42,3 \%$ afirmaram que é a "Lei que proibe o aborto e a eutanásia".

Ora, sabemos que o aborto e a eutanásia são objetos do código de Deontologia em Enfermagem e não da Lei do Exercício Profissional. Com esta posição podemos concluir que os enfermeiros, além de terem dificuldade em se posicionar sobre o amparo legal de sua prática, também não têm clareza dos princípios éticos deontológicos da enfermagem.

Permeando esta análise as indicações necessárias à melhoria da prática do enfermeiro, segundo os depoentes, estão limitados ao "aumento do $\mathrm{n}$ - de funcionários" (53,8\%); "treinamento sobre relações humanas" (23,1\%); "sistematização de um trabalho de prevenção", "tratamento e reabilitação do paciente" $(19,2 \%)$; utilização de materiais descartáveis $(26,9 \%)$; e um eficiente serviço de manutenção $(30,8 \%)$.

Os dados evidenciam o nível de visão da categoria sobre a melhoria dos serviços, cujas expectativas giram em torno da funcionalidade e particularidade do setor. Nosso ponto de vista é que tais expectativas carecem de compreensão política do espaço histórico da enfermagem, en-

* A compreensão desta colocação pode ser clarificada com a leitura do Artigo 8 da Lei 7.498, de 25/06/1986, que dispõe sobre o exercício da enfermagem. 
quanto prática social institucionalizada.

A partir do exposto e colocando no movimento desta leitura, os dados sobre o que é prioritário para os depoentes, "prestar assistência direta ao paciente $(34,6 \%)$, assistência à equipe de enfermagem $(19,2 \%)$ e examinar o paciente (7,7\%)" - Quadro 04 -, evidenciam que os enfermeiros, mesmo exercendo funções, principalmente administrativas, possuem um ideal ético-profissional voltado para as necessidades do paciente (assistência direta ao paciente) que lhe foi inculcado durante a formação.

Entendemos, no entanto, que em qualquer uma destas vertentes de interpretação da realidade é necessário refletir sobre a prática e embasá-la de ferramentas teóricas de sustentação político social, numa visão conjuntural, de forma que, também como classe trabalhadora, no contexto das relações sociais de produção, o enfermeiro e demais categorias da enfermagem possam contribuir para uma açẳo alternativa no contexto das instituições hospitalares, apesar de estas representarem micropoderes de reprodução da hegemonia dominante.

Este discurso, entretanto, contrapõe-se à posição acrítica dos depoentes quando, numa posição funcionalista de leitura da realidade, 46,2\% (Quadro 05) deixaram de se posicionar sobre os problemas do seu setor de trabalho. Merece ser inferido nesta questão a relação do poder institucional sobre o enfermeiro e as raízes histórico-culturais da profissão. E, o enfermeiro, como trabalhador indireto (isto quando interpretado a luz das relações sociais de produção), assume o papel de agente organizador, vigilante e controlador do processo de trabalho da enfermagem para que o trabalhador direto (os usuários dos serviços de saúde) possam retornar ao setor produtivo com capacidade máxima de produtividade.

Outra vertente de interpretação da posição acrítica dos depoentes perpassa pelo entendimento do poder hegemônico do modelo médico sobre as demais categorias profissionais da saúde, mantendo-se intocável às críticas, e sendo reproduzido na prática concreta da saúde institucionalizada.

Há de ser enfatizada a posição funcionalista dos enfermeiros ao definirem os agravantes dos serviços de enfermagem como sendo, basicamente, determinados por questões técnico-burocráticas (dados do Quadro 05) sem uma contextualização mais ampla da realidade.

\section{TENTATIVA DE RECONSTRUÇĀO DE UMA REALIDADE}

A postura de movimento adotada na análise e interpretação dos dados impede-nos de assumir um posicionamento conclusivo frente a rea- lidade apreendida, caracterizando-o assim, como uma fase preliminar de um estudo inesgotável; pois, a proporção que se enriquece a discussão, se constitui, ao mesmo tempo, principios geradores de novos conhecimentos.

Nesta perspectiva, resta-nos concluir que a realidade da prática de enfermagem no interior das instituições hospitalares, objeto desta pesquisa, vem esclarecer que, no âmbito desta prática, existem fenômenos que urgem ser trabalhados com vistas à construção de espaços para o desenvolvimento de atividades do enfermeiro, priorizando a enfermagem como trabalho e prática social, que tem como finalidade o produto em si. Tais fenômenos, entendemos, são produtos de uma sociedade dividida em classes de interesse antagônicos.

No concreto apreendido transparece a concentração dos leitos hospitalares no setor privado $(77,9 \%)$, deixando pois o Estado de of erecer os serviços, para ser comprador destes.

A desproporcionalidade entre o número de profissionais de enfermagem $\mathrm{X}$ leitos ofertados $(0,6 \%)$ se intensifica quando fazemos a leitura isolada da categoria enfermeiros $X$ leitos ofertados $(0,1 \%)$, deixando transparente a contradição entre o capital e o trabalho onde, as instituições hospitalares, como subestruturas do sistema capitalista, privilegiam a maximização dos lucros a partir da minimização dos custos e, portanto, espaço contraditório.

Configura-se também, nesta pesquisa, que a força de trabalho na Enfermagem é, fundamentalmente, representada por atendentes de enfermagem $(63,4 \%)$. Assim, a prática do enfermeiro dicotomiza-se entre os interesses da instituição e os interesses da profissão e necessidades dos pacientes. Esta distribuição desigual, inclusive se considerarmos as relações número de enfermeiros $\mathrm{X}$ número de leitos e número de enfermeiros dos hospitais privados $\mathrm{X}$ hospitais públicos, reforça a divisão técnica do trabalho nesta área, cabendo aos atendentes a maioria dos cuidados diretos aos pacientes, enquanto que o enfermeiro se apropria do trabalho de supervisão e controle da força de trabalho manual. Com isto, o enfermeiro assume o papel de trabalhador intelectual, reprodutor dos objetivos da instituição como forma de adaptar-se ao modo de produção vigente.

A ideologia do capital de divisão de classes é reforçada pelo contingente feminino $(96,3 \%)$ nas categorias de trabalhadores da Enfermagem que é historicamente determinada pelas tipologias sexuais que privilegiam as funções desenvolvidas pelo sexo masculino, disto advindo o barateamento da força de trabalho na enfermagem e os entraves aos avanços na prática do enfermeiro.

A concentração do poder do conhecimento médico sobre as demais categorias profissionais 
de saúde e a conjuntura do sistema hospitalar que não se diferencia da conjuntura social são fatores, a luz dos quais, pode ser analisada a prática do enfermeiro nos hospitais e, até certo ponto, justifica o posicionamento acrítico dos depoentes sobre as questões investigadas e a concentração de atividades do enfermeiro em funções administrativas. Estas, por sua vez, contrapōem-se aos princípios éticos profissionais do enfermeiro enquanto colocam entre suas principais atividades o cuidado direto ao paciente. Contraditoriamente a esta posição, os enfermeiros não conseguiram reconhecer na Lei do Exercício Profissional as competências do "cuidar" que lhes são atribuídas.

Com estas posições merece ser enfocada nossa aspiração de que o enfermeiro não apenas ocupe o lugar que lhe é designado, mas que crie o seu próprio espaço nas instituições hospitalares e se faça sujeito de sua ação e de sua história. Isto, no entanto, só ocorrerá com posições fundamentadas teoricamente e com organização da categoria, servindo de força de pressão frente 0 sistema vigente.
Isto posto, reflete na disfuncionalidade do universo pesquisado, a necessidade de emitirmos sugestões que atentem para a reflexão da prática do enfermeiro e que venham contribuir para a análise e implementação de atividades de enfermagem, via prática político-educativa, de forma que se possa adquirir, através das ferramentas teóricas, subsídios para o conhecimento da realidade no seu aspecto estrutural e conjuntural:

- refletir e debater sobre o cotidiano da prática do enfermeiro na instituição hospitalar de forma a se estabelecer alianças comprometidas com a ótica do trabalho e não com a ótica do capital, onde, instiga-se o enfermeiro a auto-reflexão crítica na atomização da realidade (cuidado direto $\mathrm{X}$ funções gerenciais);

- a organização da prática da enfermagem, via participação de classe, numa correlação de forças internas e externas, na busca de ampliação do espaço profissional, via ampliação da força de trabalho na Enfermagem, perpassando pelas questōes inerentes à própria formação do enfermeiro (ensino de graduação).

\section{REFERÊNCIAS BIBLIOGRÁFICAS}

1 ALMEIDA, Maria Cecília Puntel, ROCHA, Juan Stuardo Yazlle. $O$ saber de Enfermagem e sua dimensão prática. São Paulo: Cortez, 1986. 128p.

2 BRASIL - Conselho Federal de Enfermagem. O Exercício da Enfermagem nas Instituiçōes de Saúde no Brasil: 1982-1983. Rio de Janeiro. COFEN/ABEN, 1985. v.1; $236 \mathrm{p}$.

3 LÖWY, Michel. Método Dialético e Teoria Política. (Tradução de Reginaldo de Piero). 4. ed., Rio de Janeiro: paz e Terra, 1989. 141p.

4 LUZ, Madel Terezinha. As Instituiçōes Médicas no Brasil: instituiçôes e estratégias de hegemonia. 3. ed. Rio de Janeiro: Graal, 1986. 265 p.

5 MARX, Karl. O Capital: Crítica da economia política. (Tradução de R. Kathe) 3. ed., São Paulo: Nova Cultural, $1.1,1988$.

$6 \mathrm{MELO}$, Cristina. Divisão Social do Trabalho e Enfermagem. São Paulo: Cortez, 1986. 94 p.
7 NAKAMAE, Djair Daniel. Novos Caminhos da Enfermagem. São Paulo: Cortez, 1987. 120 p.

8 PAIXÃO, Waleska. História da Enfermagem. 5. ed. Rio de Janeiro: Júlio C. Reis, 1979. 141 p.

9 SANDRONI, Paulo (org.) Dicionário de Economia. 3. ed. São Paulo: Best Seller, 1989. 331 p.

10 SILVA, Nair Fábio. O objetivo e a prática de Enfermagem. In: Anais do IV Encontro Nacional de Enfermagem Fundamental. Salvador, Escola de Enfermagem da UF$\mathrm{Ba} / \mathrm{FAPEX}, 1988$.

11 SPOSA Г ГI, Aldaiza Oliveira (Coordenadora). A assistência social no Brasil: 1983 - 1990. São Paulo: Cortez, 1991. $94 \mathrm{p}$.

12 TEIXEIRA, Fleury Sônia (org.) Reforma Sanitária em busca de uma teoria. São Paulo: Cortez, vv. 3, 232 p.

13 TREVIZAN, Maria Auxiliadora. Enfermagem Hospitalar Adninistração e Burocracia. Brasília-DF: Universidade de Brasília, 1988. 142 p. 
ANEXO 1 - Roteiro de Entrevistas/Visitas aos Hospitais de Mossoró

\section{I - Dados da Instituiçāo}

1. Denominação:

2. Vinculação administrativa:

( ) órgão govemamental

( ) privado

3. Característica:

$$
\text { () Geral }
$$

4. Capacidade: $n^{\circ}$ de leitos

5. Força de trabalho na Enfermagem:
a) No de enfermeiros:
b) № de técnicos:
c) № de auxiliares:
d) № de atendentes:
Masc:
Masc:
Masc:
Masc:

) Especializado (especificar)

II - Dados a serem fornecidos pelo enfermeiro:

1. Enfermeiro:

2. Cargo ou função:

3. Setor de trabalho:

4. Seu setor de trabalho possui documentação sob a forma de:

( ) Regulamentos/regimentos

) Organogramas

) Manuais de normas/rotinas e competências do setor

) Outros (especificar)

5. Liste 10 problemas que você observa no setor:

6. Dê sugestões para a solução desses problemas:

7. Liste 10, das atividades que você desenvolve no setor:

8. Das atividades acima, quais as que você considera prioritárias para a prática do enfermeiro? Justifique: 
9. A prática profissional do Enfermeiro está legalmente respaldada na Lei no 7.497 de 25 de junho de 1986.

-Que conhecimento você tem sobre a Lei do Exerć́cio Profissional da Enfermagem? Especifique as atribuições do Enfermeiro em nível administrativo e em nível de assistência:

Mossoró, $/ / 1991$ 